\title{
DEMİR ESASLI ŞEKİL HAFIZALI ALAŞIMLAR
}

\author{
Kemal NURVEREN ${ }^{1, *}$ \\ Makine Mühendisliği Bölümü, Mühendislik Fakültesi, Niğde Üniversitesi, 51240, Niğde, Türkiye
}

\begin{abstract}
ÖZET
Şekil hafizalı alaşım terimi, uygun ısıl ve mekaniksel prosedürlere maruz kaldığında önceden tanımlı şekil veya boyutuna geri dönebilme yeteneği gösteren metalik malzeme grupları için kullanılır. Şekil hafizalı alaşımlar kararlı iki faza sahiptir. Bu fazlar ostenit olarak isimlendirilen yüksek sıcaklık fazı ve martenzit olarak isimlendirilen düşük sıcaklık fazıdır. Esas itibari ile şekil hafızalı alaşımlar üç ana grupta toplanabilir. Bunlar nikel-titanyum esaslı, bakır esaslı ve demir esaslı şekil hafızalı alaşımlardır. Bu çalışmada demir esaslı şekil hafızalı alaşımlara genel olarak değinilmiştir.
\end{abstract}

Anahtar Kelimeler: Demir esaslı şekil hafizalı alaşım, şekil hafıza etkisi, martenzitik dönüşüm.

\section{FERROUS SHAPE MEMORY ALLOYS}

\begin{abstract}
The term of shape memory alloy is applied to that group of metallic materials that demonstrate the ability to return to some previously defined shape or size when subjected to the appropriate thermal and mechanical procedures. The shape memory alloys have two stable phases - the high temperature phase, called austenite and the low temperature phase, called martensite. Actually, there are three main group of the shape memory alloys. These are nickel-titanium based, copper based, and ferrous shape memory alloys. This study gives an overview of the ferrous shape memory alloys.
\end{abstract}

Keywords: Ferrous shape memory alloy, shape memory effect, martensitic transformation.

\section{GİRIŞ}

Teknik olarak uygun bir ısıl işlem ile gerçek şekline geri dönebilme yeteneğine sahip metalik malzemeler şekil hafızalı alaşımlar olarak isimlendirilir. Şekil hafizalı alaşımlar 1sıl değişimlere duyarlı fonksiyonel malzemelerdir. Bu alaşımların temel karakteristiği, kritik dönüşüm sıcaklığının üstünde ve altında iki farklı şekil veya kristal yapısına sahip olmalarıdır [1].

Şekil hafizalı alaşımlar, uygulanan sıcaklık ya da yük karşısında şeklini değiştirebilen malzemeler olduğundan teknolojik açıdan büyük ilgi çekmektedir. Bu tür malzemelerde görülen şekil hafiza etkisi, süper elastiklik, yüksek sönümleme kabiliyeti, korozyon dayanımı ve biyouyumluluk gibi üstün fonksiyonel özellikler sayesinde birçok endüstriyel ve tıbbi uygulamalarda yaygın bir kullanım potansiyeline sahip olmaktadır [2].

Uygulamada şekil hafiza etkisi gösteren çok sayıda alaşım olduğu bilinmekle birlikte bunlar arasında en çok ilgi görenler nikel-titanyum esaslı, bakır esaslı ve demir esaslı şekil hafızalı alaşımlardır [3].

*Tel.: +90 (532) 51645 57; fax: +90 (388) 22501 12. e-mail: knurveren@nigde.edu.tr 


\section{MARTENZITIIK DÖNÜŞÜM}

Martenzit ilk olarak su verilmiş çeliklerin içyapısında gözlemlenmiştir. Çelik bir malzemeye yüksek sıcaklıkta ostenitik fazdan su verilirse martenzit meydana gelmektedir. Kübik yüzey merkezli ostenit bölgeler, kübik hacim merkezli ya da tetragonal hacim merkezli kafeslere sahip mercek veya tabak şeklindeki bölgelere dönüşmektedir. Böyle dönüşümlerle ortaya çıkan kristaller "martenzit", atomik difüzyonsuz kafes dönüşümleri ise "martenzitik dönüşümler" olarak isimlendirilmektedir. Difüzyonsuz martenzitik dönüşümler çelik dışında pek çok metal, alaşım ve bileşiklerde de gözlemlendiğinden dolayı günümüzde "martenzitik dönüşüm” terimi yaygın olarak kullanılmaktadır.

Martenzitik dönüşüm difüzyonsuzdur. Dönüşüm sonrasında belirli bir miktarda şekilsel değişim veya yüzeysel gevşeme gözlemlenir. Martenzit faz içerisinde çözünen atomların derişimi, ana fazda çözünen atomların derişimine eşittir. Ötektoid dönüşümlerde görülen uzun mesafeli difüzyon olayı görülmez [4]. Mikroskobik şekil değişimlerine neden olan bir kafes çarpılması söz konusudur [5]. Ana faz ve martenzit faz kafesleri arasında belirli bir yönelim ilişskisi ve habit düzlemleri vardır. Kafes hatalarının varlı̆̆ martenzit kristallerinde kaçınılmazdır.

\subsection{Termoelastik Martenzitik Dönüşüm}

Şekil 1.'de Fe-30at.\%Ni ve Au-47.5at.\%Cd için, alaşımların martenzitik ve tersinir dönüşümleri hakkında bilgi veren elektrik direncindeki değişimin sıcaklık ile ilişkisi görülmektedir. FeNi alaşımında, dönüşüm sıcaklığının histerezisi yani ostenitin başlangıç sıcaklığı ile martenzitin başlangıç sıcaklıkları arasındaki fark $\left(A_{s}-M_{S}\right)$ aşırı büyük olup (yaklaşık $400^{\circ} \mathrm{C}$ ), AuCd alaşımında ise bu değer çok küçüktür (sadece $15^{\circ} \mathrm{C}$ ). Bu da göstermektedir ki, itici kuvvet ve bu nedenle dönüşümün gereksindiği kimyasal olmayan serbest enerji FeNi alaşımında büyük, AuCd için ise oldukça küçüktür. AuCd alaşımında, ara yüzey enerjisinin ve plastik deformasyon için gereken enerjinin ihmal edilecek kadar küçük olması bunun bir nedeni olarak düşünülmektedir.

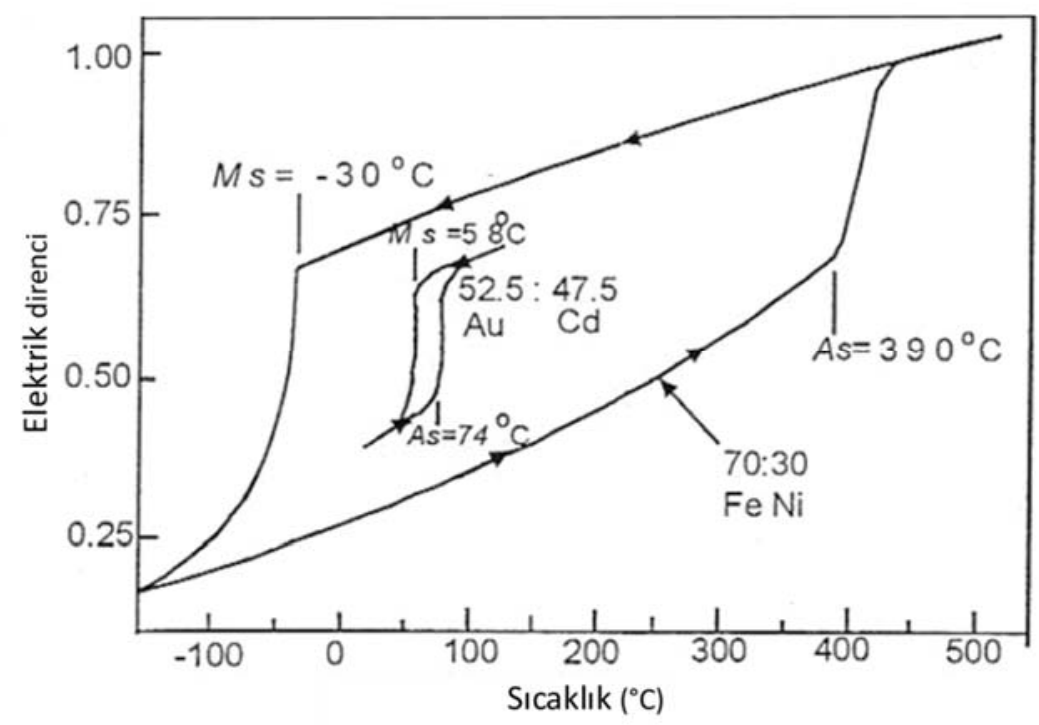

Şekil 1. Termoelastik olan $(\mathrm{AuCd})$ ve olmayan (FeNi) martenzit dönüşümler için sicaklık döngülerinin karşılaştırılması [4].

Termoelastik dönüşümün meydana gelmesi için hem ara yüzey enerjisi, hem de plastik deformasyon için duyulan enerji ihmal edilebilecek kadar küçük olmalıdır. Bu durum dönüşüm esnasında yapısal değişikliklerin ve dolayısı ile hacimsel değişimlerin küçük olmasıyla ve ayrıca P (veya A) ana fazı ile M martenzit fazı kafesleri arasında iyi bir eşleşme olmasıyla mümkündür [4]. 


\subsection{Deformasyon Nedenli Martenzitik Dönüşüm}

Deformasyon nedenli dönüşümün iki durumu söz konusudur. $M_{s}$ üzerindeki bir sıcaklıkta deformasyon uygulanması durumunda martenzit, akma gerilmesinden daha küçük değerde olan gerilmeler altında çekirdeklenmekte ve büyüyebilmektedir. $\mathrm{Bu}$ yolla oluşan martenzit "gerilme nedenli" martenzit olarak adlandırılır. Burada olası bir plastik gerinim, dönüşümün plastisitesinden dolayıdır. Oluşan martenzitin hacimsel oranı, var olan gerinim ile doğrusal olarak ilişkilidir. Martenzitin oluşmaya başladığı gerilme değeri ise sıcaklıkla birlikte artmaktadır. Bu durum aşağıdaki 1 no.lu Clausius-Clapeyron denklemi ile açıklanabilir.

$$
\frac{d \sigma^{p-m}}{d T}=\frac{\Delta S}{\varepsilon_{\text {maks }}}
$$

Denklemde, $\sigma^{P-M}$ martenzitin oluşmaya başladığı gerilme değeri, $\Delta S$ entropideki değişim ve $\varepsilon_{\text {maks }}$ ise plastik deformasyon olmaksızın martenzitin kayma unsuru ile büyümesinden dolayı elde edilen maksimum gerinim miktarıdır. Eğer $\sigma^{P-M}, \sigma_{y}$ akma gerilmesi değerine ulaşırsa, $M_{s}^{\sigma}$ sıcaklığı en yüksek değerine ulaşır ve dönüşüm sadece elastik gerilmeler ile bile başlayabilecek duruma gelir. $M_{s}^{\sigma}$ sıcaklığının üstündeki sıcaklıklarda martenzit oluşmadan evvel plastik akış meydana gelir.

Gerinim uygulanması durumunda martenzit büyümeye devam ederken, yeni yeni gerinim nedenli çekirdekleşen martenzitik bölgeler meydana gelir. Gerinim nedenli martenzitin meydana geldiği gerilme değeri, deformasyon nedenli martenzitin oluşabildiği en yüksek sıcaklık değeri olan $M_{d}$ değerine ulaşılana dek artan sıcaklıkla akma gerilmesi eğrisinden daha çok sapma gösterir. Bu sıcaklığın üstünde, uygulanan deformasyon sonucu martenzit oluşumu gözlenmez.

Gerilme nedenli martenzit oluşumu, termoelastik martenzitik dönüşüm gösteren şekil hafizalı alaşımlarda görülen "sözde elastiklik" davranışının orijinidir. Gerilme nedenli martenzit oluşumu olayında kalıcı deformasyon olmadığından dolayı, $A_{f}$ sıcaklığının üstündeki bir sıcaklıkta $\varepsilon_{\text {maks }}$ değerinde bir maksimum deformasyon tatbik edilirse, hacimsel kesri \%100 olan bir martenzit elde edilmiş olur. Uygulanan yükün kaldırılması durumunda, yükün neden olduğu gerinim tamamen toparlanır ve yeniden ana faza doğru tersine dönüşüm gerçekleşir (Şekil 2). Bu sözde elastik davranış, ileriki bölümlerde daha detaylı anlatılacak olan NiTi gibi şekil hafızalı alaşımların en başarılı fonksiyonel özelliklerinden birisidir. Çok kristalli bir NiTi alaşımda, \%8 gibi oldukça büyük değerlerde toparlanabilir gerinimlerin olduğu görülmüştür [5].

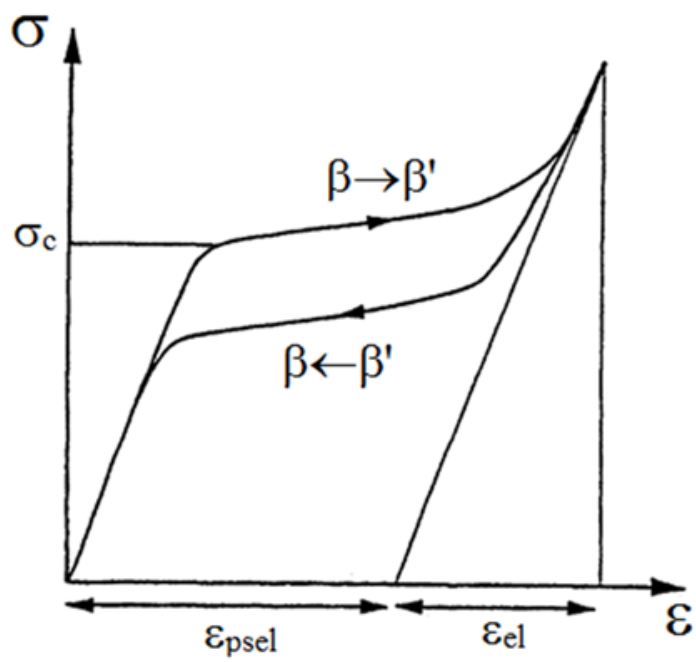

Şekil 2. Gerilme nedenli martenzit yoluyla sözde elastik deformasyonun şematik çizimi [5]. 


\subsection{Martenzit Dönüşümün Basit Modeli}

Martenzitik faz dönüşümü ile ortaya çıkan mikro yapının önceden tahmin edilebilirliği, malzeme bilimindeki temel problemlerden biridir. Martenzite göre daha yüksek bir kristal simetrisine sahip olan ostenitik ana fazın dönüşümü sonucunda, emsalsiz bir dizi, kafes etkileşimli martenzitik varyantların oluşumu gözlenir. Ana fazdan martenzite dönüşüm esnasında meydana gelen kafes deformasyonları, açığa çıkan gerinimin en aza düşürüleceği bir yolda dönüşümü ilerlemeye zorlar [6]. Oluşan martenzitik varyantlar kendi yerleşimlerini düzenleyen bir yapısal hareketlenme ile söz konusu gerinim enerjisini azaltıcı bir rol oynamaktadır. Numuneye bir yük uygulandığında, maksimum miktarda toparlanabilir gerinim değerine ulaşılana dek martenzitik varyantlar kendi yer düzenlerini ayarlarlar. Uygulanmış olan yük kaldırıldığında dahi var olan gerinim mevcudiyetini korur. Deformasyona uğramış olan numunenin $A_{f}$ üstündeki bir sıcaklık değerine 1sıtılması ile tersine martenzitik dönüşüm gerçekleşerek orijinal şekil, tamamen geri kazanılmış olur.

Şekil 3.'de martenzitik dönüşümün basitleştirilmiş bir modeli şematik olarak çizilmiştir. Sıcaklık $M_{s}$ noktasının altına düştüğünde, kesme tarzındaki bir mekanizma ile martenzitik dönüşüm tekrar başlar. A ve B bölgelerindeki martenzit aynı yapıya sahiptir ancak yönelimleri birbirinden farklıdır. Her biri etkileşimli martenzitik varyant olarak adlandırılır. Martenzit daha düşük bir kristal simetrisine sahip olduğundan dolayı aynı ana fazdan pek çok martenzitik varyant oluşabilir. Sıcaklık yükseldiğinde ise martenzit kararsız hale gelir ve tersine martenzitik dönüşüm başlar. Eğer kristalografik açıdan tersinebilirlik söz konusu ise martenzit, orijinal yönde ana faza geri döner. Atomik yer değiştirmeler çok küçük olmasına karşın, tersine martenzitik dönüşüm esnasındaki yapısal değişimlerden dolayı mikroskobik bir şekil değişimi gözlemlenir [7].

(b) $\mathrm{T}<\mathrm{M}_{\mathrm{s}}$

(a) $T>A_{f}$

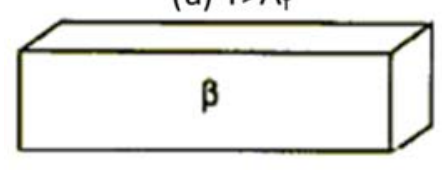

Isıtma

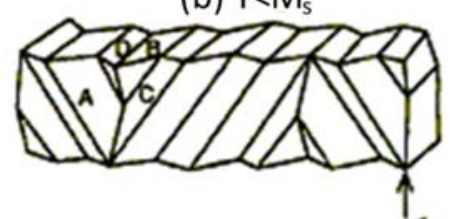

(c) $\mathrm{T}<\mathrm{M}_{\mathrm{f}}$
Deformasyon

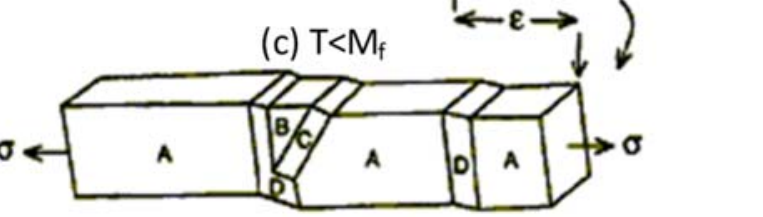

Şekil 3. Martenzitik dönüşümün resimlemesi [7].

\subsection{Demir Esaslı Alaşımlardaki Martenzitte Morfoloji ve Temel Yapı}

Demir esaslı alaşımlarda, KYM ostenit $(\gamma)$, alaşım elementlerine bağlı olarak farklı kristal yapılara sahip olan üç çeşit martenzite dönüşür. Bunlar (1) $\gamma \rightarrow \alpha$ ' (KHM veya THM) martenzit, (2) $\gamma \rightarrow \varepsilon$ (HSP) martenzit ve (3) $\gamma \rightarrow$ TYM martenzit. En popüler demirli martenzit Fe-C ve Fe-Ni gibi alaşımlarda şekillenen $\alpha$ ' martenzittir. $\varepsilon$ martenzit sadece osteniti düşük yığılma hatası enerjisine sahip olan Fe-Cr-Ni ve Fe-yüksek Mn gibi alaşımlarda meydana gelir. TYM martenzit ise çok nadir görülür ve sadece Fe-Pd ve Fe-Pt alaşımlarında gözlenmektedir.

$\varepsilon$ ve TYM martenzitlerin morfolojisi düzlemsel ara yüzlere sahip paralel kenarlı ince plakalar şeklindedir. Öte yandan, $\alpha$ ' martenzitte şimdiye kadar beş çeşit morfoloji olduğu rapor edilmiştir. Şekil 4, $\alpha$ ' martenzit ve $\varepsilon$ martenzit morfolojilerini göstermektedir. $\alpha$ martenzitlerin beşi de hem morfolojik açıdan hem de kristalografik açıdan farklılık göstermektedir. Bu $\alpha$ martenzitler arasında, çıta martenzit en yüksek sıcaklıklarda, ince plaka şeklindeki martenzit ise en düşük sıcaklıklarda şekillenmektedir. Ms sıcaklığındaki azalmayla martenzitin yapısı dislokasyonlu (çıta martenzit) halden ikizlenmiş (ince plaka martenzit) hale değişir. $\alpha$ martenzitin morfolojisini ve yapısını belirleyen faktörler tam olarak tanımlanamamaktadır. Ancak, Ms sıcaklığı, ostenitin ve martenzitin nispi dayanımları, martenzitte kayma ve ikizlenme için kritik kesme gerilmesi ve ostenitin yığılma hatası enerjisi önemli faktörler olarak düşünülmektedir. 

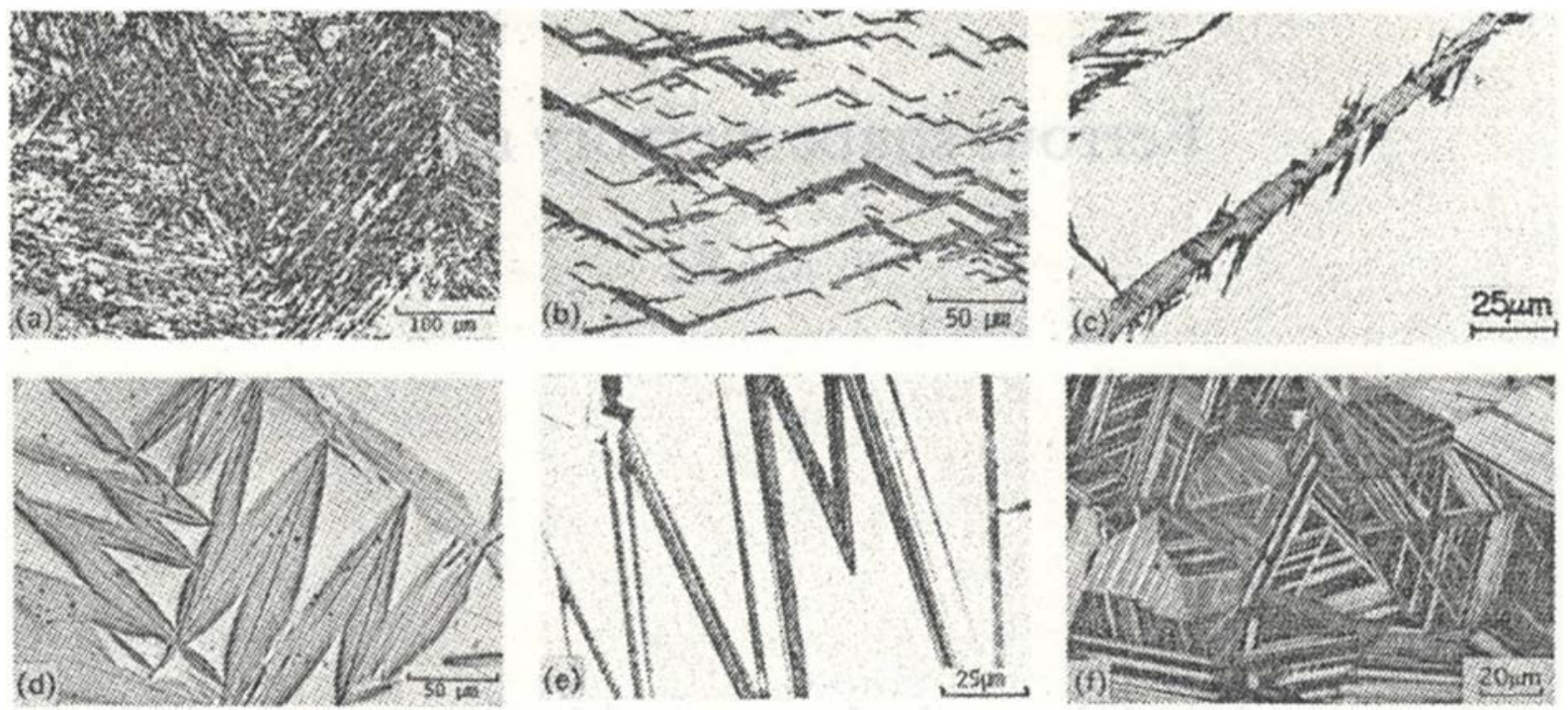

Şekil 4. Demir esaslı alaşımlarda görülen değişik tipteki martenzitlere ait optik mikrograflar: (a) çıta $\alpha$ ' (Fe$7 \% \mathrm{Ni}-0.22 \% \mathrm{C})$, (b) kelebek $\alpha$ (Fe-20\%Ni-0.73\%C), (c) (225) tipi plaka $\alpha$ (Fe-8\%Cr-0.92\%C), (d) mercimek $\alpha^{\prime}(\mathrm{Fe}-29 \% \mathrm{Ni}-0.26 \% \mathrm{C}),(\mathrm{e})$ ince plaka $\alpha$ ' $\left.\mathrm{Fe}-31 \% \mathrm{Ni}-0.23 \% \mathrm{C}\right),(\mathrm{f}) \varepsilon$ martenzit $(\mathrm{Fe}-24 \% \mathrm{Mn})[8]$.

Çıta ve mercek şeklinde görülen martenzit türleri, $\alpha$ martenzite ait iki önemli morfolojidir. Çıta martenzit Fe$\mathrm{C}(<0.6 \% \mathrm{C})$ ile $\mathrm{Fe}-\mathrm{Ni}(<28 \% \mathrm{Ni})$ alaşımlarında ve pek çok 1 ș1 işlem uygulanabilen ticari durumlarda şekillenmektedir. Ayrıca yüksek dayanımlı çeliklerin temel yapısı olduğundan çok fazla endüstriyel öneme sahiptir. Merceksel martenzit Fe-C(0.8 1.8\%) ve Fe-Ni(29 33\%) alaşımlarında görülmektedir. Diğer üç $\alpha$ ' martenzit demir esaslı alaşımlarda yaygın değildir. Bununla birlikte, beş çeşit olan $\alpha$ martenzitler arasında ince plaka martenzit mükemmel bir şekil hafıza etkisi sergileme imkânına sahiptir. Şekil 5.'de Fe-31\%Ni-0.3\%C alaşımında ince plaka martenzitin transmisyon elektron mikrografi görülmektedir [9].

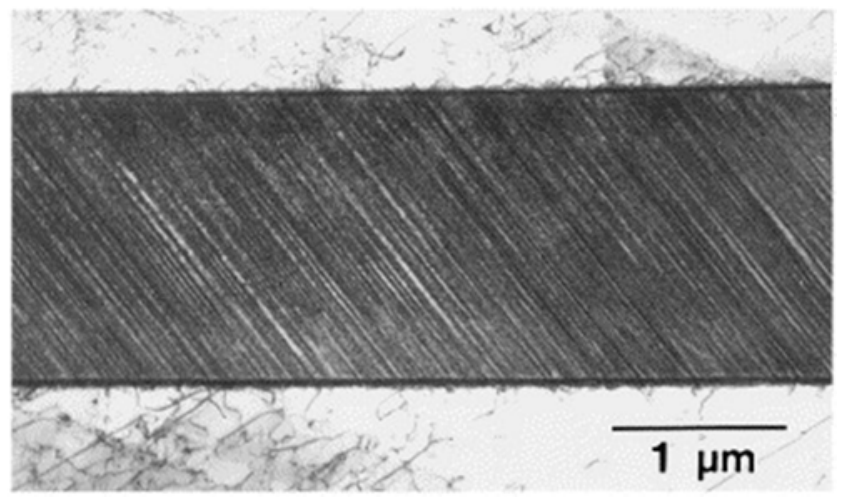

Şekil 5. Fe-31\%Ni-0.3\% C alaşımında ince plaka martenzitin transmisyon elektron mikrografi [9].

\section{3. ŞEKILL HAFIZA ETKİSI GÖSTEREN DEMİR ESASLI ALAŞIMLAR}

Tablo 1.'de, literatürde şimdiye kadar rapor edilmiş olan mükemmel ya da mükemmele yakın şekil hafiza etkisi sergileyen demirli alaşımlara ait bilgiler özetlenmiştir. Fe-Pt alaşımı haricindeki diğer tüm demirli şekil hafızalı alaşımlar ana fazda düzensiz yapıya (KYM) sahiptir. Fe-Pt, Fe-Pd ve Fe-Ni-Co-Ti alaşımlarında, ostenite uygun olarak ısıl işlem uygulanırsa küçük ısıl histerezisli bir termoelastik martenzitik dönüşüm meydana 
gelir. Fe-Ni-C ve Fe-Mn-Si-(Cr) gibi diğer alaşımlarda termoelastik martenzitik olmayan bir dönüşüm meydana geldiği görülmektedir.

$\alpha$ (KHM veya THM) martenzit durumunda, ostenit matrisi düzenli olduğunda $\left(\mathrm{Ll}_{2}\right) \mathrm{Fe}-25 \mathrm{at} \% \mathrm{Pt}$ alaşımı mükemmel bir şekil hafiza etkisi göstermektedir. Bu alaşım, bulunan ilk demirli şekil hafizalı alaşımdır. $\mathrm{Bu}$ alaşımda martenzitik dönüşüm, ostenitin uzun aralıklı düzen derecesindeki artışla birlikte termoelastik olmayan (patlama tipi) bir türden termoelastik bir türe dönüşür. Ayrıca, Fe-23\%Ni-10\%Ti alaşımı, ostenit halde yaşlandırıldığında şekil hafıza etkisi göstermektedir. Uygun bir şekilde östemperlenen ve ince koherent düzenli çökeltiler ( $\gamma-\mathrm{Ni}_{3} \mathrm{Ti}\left(\mathrm{L}_{2}\right.$ tipi)) içeren $\mathrm{Fe}-33 \% \mathrm{Ni}-10 \% \mathrm{Co}-4 \% \mathrm{Ti}$ alaşımı termoelastik davranış sergilemekte, bundan dolayı mükemmel şekil hafiza etkisi ve süper elastiklik özelliklerine sahip olmaktadır. Östemperlenmiş Fe-32\%Ni-12\%Co-4\%Ti alaşımı iki yönlü şekil hafıza etkisi göstermektedir. Fe-31\%Ni-0.4\%C alaşımında martenzit termoelastik tip olmamasına karşın östemperleme ile ostenitin dayanımı artırıldı̆̆ zaman hemen hemen mükemmel bir şekil hafiza etkisi göstermektedir. $\gamma$ " $-\mathrm{Ni}_{3} \mathrm{Nb}\left(\mathrm{D}_{22}\right.$ tip) partiküller içeren östemperlenmiş $\mathrm{Fe}-31 \% \mathrm{Ni}-7 \% \mathrm{Nb}$ alaşımında mükemmel bir şekil hafiza etkisi göstermektedir.

Tablo 1. Mükemmel ve mükemmele yakın şekil hafıza etkisi sergileyen demirli alaşımlar. [8]

\begin{tabular}{|c|c|c|c|}
\hline $\begin{array}{l}\text { Martenzitin } \\
\text { kristal yapıs1 }\end{array}$ & Alaşım & Bileşim & $\begin{array}{c}\text { Dönüşümün } \\
\text { doğası }\end{array}$ \\
\hline \multirow{4}{*}{$\begin{array}{l}\text { KHM veya } \\
\text { THM } \\
\left(\alpha^{\prime}\right)\end{array}$} & $\begin{array}{c}\text { Fe-Pt } \\
\text { (düzenli } \gamma \text { ) }\end{array}$ & $\approx 25 \mathrm{at} \% \mathrm{Pt}$ & TE \\
\hline & $\begin{array}{c}\text { Fe-Ni-Co-Ti } \\
\text { (ostemperlenmiş } \gamma \text { ) }\end{array}$ & $\begin{array}{l}23 \% \mathrm{Ni}-10 \% \mathrm{Co}-10 \% \mathrm{Ti} \\
33 \% \mathrm{Ni}-10 \% \mathrm{Co}-4 \% \mathrm{Ti} \\
31 \% \mathrm{Ni}-10 \% \mathrm{Co}-3 \% \mathrm{Ti}\end{array}$ & $\begin{array}{c}- \\
\text { TE } \\
\text { TE olmayan }\end{array}$ \\
\hline & $\begin{array}{c}\text { Fe-Ni-C } \\
\text { (ostemperlenmiş } \gamma \text { ) }\end{array}$ & $31 \% \mathrm{Ni}-0.4 \% \mathrm{C}$ & TE olmayan \\
\hline & $\begin{array}{c}\text { Fe-Ni-Nb } \\
\text { (ostemperlenmiş } \gamma \text { ) }\end{array}$ & $31 \% \mathrm{Ni}-7 \% \mathrm{Nb}$ & TE olmayan \\
\hline \multirow[t]{2}{*}{$\begin{array}{l}\mathrm{HSP} \\
(\varepsilon)\end{array}$} & $\mathrm{Fe}-\mathrm{Mn}-\mathrm{Si}$ & $\begin{array}{c}30 \% \mathrm{Mn}-1 \% \mathrm{Si} \\
\text { (tek kristal) } \\
(28 \sim 33) \% \mathrm{Mn}-(4 \sim 6) \% \mathrm{Si}\end{array}$ & $\begin{array}{l}\text { TE olmayan } \\
\text { TE olmayan }\end{array}$ \\
\hline & $\begin{array}{c}\text { Fe-Cr-Ni-Mn-Si } \\
\text { Fe-Mn-Si-C }\end{array}$ & $\begin{array}{c}9 \% \mathrm{Cr}-5 \% \mathrm{Ni}-8 \% \mathrm{Mn}-6 \% \mathrm{Si} \\
13 \% \mathrm{Cr}-6 \% \mathrm{Ni}-8 \% \mathrm{Mn}-6 \% \mathrm{Si}-12 \% \mathrm{Co} \\
8 \% \mathrm{Cr}-5 \% \mathrm{Ni}-20 \% \mathrm{Mn}-5 \% \mathrm{Si} \\
12 \% \mathrm{Cr}-5 \% \mathrm{Ni}-16 \% \mathrm{Mn}-5 \% \mathrm{Si} \\
17 \% \mathrm{Mn}-6 \% \mathrm{Si}-0.3 \% \mathrm{C}\end{array}$ & $\begin{array}{l}\text { TE olmayan } \\
\text { TE olmayan } \\
\text { TE olmayan }\end{array}$ \\
\hline TYM & $\begin{array}{l}\mathrm{Fe}-\mathrm{Pd} \\
\mathrm{Fe}-\mathrm{Pt}\end{array}$ & $\begin{array}{l}\approx 30 \mathrm{at} \% \mathrm{Pd} \\
\approx 25 \mathrm{at} \% \mathrm{Pt}\end{array}$ & $\begin{array}{l}\text { TE } \\
\text { TE }\end{array}$ \\
\hline
\end{tabular}

TE: Termoelastik martenzit

$\gamma \rightarrow \varepsilon$ martenzitik dönüşüme maruz kalan Fe-Mn-Si şekil hafizalı alaşımlar da mevcuttur. Tek kristalli Fe$30 \% \mathrm{Mn}-1 \% \mathrm{Si}$ alaşımı özel bir doğrultuda deforme edildiğinde tam bir şekil hafiza etkisi sergilemektedir. Şekil hafiza etkisinin orijini gerilme nedenli ع'un tersine bir dönüşümü sonucudur. Çok kristalli Fe-Mn-Si şekil hafizalı alaşımlar da geliştirilmiştir. Ayrıca iyi korozyon direncine sahip olan paslanmaz Fe-Cr-Ni-Mn-Si-(Co) şekil hafizalı alaşımlar geliştirilmiş̧ir. Fe-Mn-Si alaşımlarına $\mathrm{C}$ eklenmesinin şekil hafiza etkisinin iyileştirilmesinde çok etkili olduğu gözlemlenmiştir. $\varepsilon$ martenzit durumunda, dönüşüm termoelastik olmadığından dolayı ileri ve tersine dönüşümlerin 1 sıl histerezisi oldukça büyüktür.

TYM martenzit durumunda, Fe- 30at\%Pd alaşımında ardışık $\mathrm{KYM} \rightarrow \mathrm{TYM} \rightarrow \mathrm{THM}$ şeklinde martenzit dönüşüm meydana gelmekte ve $\mathrm{KYM} \rightarrow \mathrm{TYM}$ dönüşümün şekil hafiza etkisi eşliğinde termoelastik olduğu 
görülmektedir. Yine ayrıca düzenli Fe-25at.\%Pt alaşımında termoelastik KYM $\rightarrow$ TYM martenzitik dönüşüm ile ilişkili şekil hafiza etkisi olduğu bulunmuştur.

Termoelastik olmayan martenzite ilişkin şekil hafiza etkisinin orijini gerilme nedenli martenzitlerin tersine dönüşümüdür. Bu durumda, mükemmel bir şekil hafıza etkisi elde etmek için iki gerekli koşul vardır. Bunlardan birincisi, deformasyon kayma olmaksızın sadece gerilme nedenli martenzitik dönüşüm ile gerçekleşir. Bu yüzden ostenit matrisin akma gerilmesinin oldukça yüksek olması arzu edilir. İkinci koşul ise gerilme nedenli martenzitin şekil gerinimi tamamen tersinebilirdir. Bunun için, martenzit ara yüzünün hareketli olması gereklidir ve martenzit ara yüzünün hareketi ile ileri ve tersine dönüşümler meydana gelir. Tersinebilir hareket için düzlemsel bir martenzit ara yüzünün gerekli olduğu görülmektedir. Tablo 1'de verilen demir esaslı şekil hafizalı alaşımların tümünün martenzit morfolojisi, düzlemsel ara yüzlü ince plaka tipindedir [8].

\section{SONUÇLAR}

İkili alaşımların özelliklerini geliştirmek için çeşitli üçlü alaşım sistemleri üzerinde çalışmalar halen devam etmektedir. Son zamanlarda, şekil hafiza etkisi gösteren nikel-titanyum esaslı ve bakır esaslı alaşımlar dışında demir esaslı şekil hafizalı alaşımlar üzerine de yoğun çalışmalar yapılmaktadır. Bu tip alaşımlarda görülen uzun aralıkta düzenlenen termoelastik martenzitik dönüşüm, şekil hafiza etkisi için gerekli koşulları sağlamaktadır. Bu alaşımlar arasında FePt, FePd ve FeNiCoTi ısıl işlemle termoelastik martenzitik dönüşüme sahip olduklarından eğitilerek şekil hafiza özelliği kazandırılabilmektedir. Ancak FeNi, FeMnSi ve FeMnSiCrNi gibi demir esaslı alaşımlar düzenli termoelastik olmayan bir martenzitik dönüşüme uğrarlar ve mükemmel bir şekil hafiza etkine sahip değildirler. Bu tür alaşımlar diğer bilinen şekil hafızalı alaşımlardan karakteristik açıdan farklıdırlar.

\section{KAYNAKLAR}

[1] NURVEREN, K., AKDOĞAN, A., "Şekil Hafizalı Alaşımlar ve Temel Özellikleri”, MakinaTek, 64, 52-58, 2003.

[2] NURVEREN, K., AKDOĞAN, A., "NiTi Şekil Hafizalı Alaşım Üretimi”, MakinaTek, Aralık, 98-104, 2005.

[3] AKDOĞAN A., NURVEREN, K., "Şekil Hafizalı Alaşımlar”, Mühendis ve Makina, 521, 35-44, 2003.

[4] FUNAKUBO, H., Shape Memory Alloys, Gordon and Breach Science Publishers, (Translated from the Japanese., J.B.Kennedy), New York, 1984.

[5] HUMBEECK, J.V., "Phase Transformations", Mechanical Spectroscopy, 382-415, 2001.

[6] WAITZ, T., "The Self-Accommodated Morphology of Martensite in Nanocrystalline NiTi Shape Memory Alloys", Acta Materialia, 53, 2273-228, 2005.

[7] LAI, B.K., "Characterization of TiNi Films for MEMS Applications", PhD. Thesis, Case Wastern Reserve University, UMI Number: 3118138, 2004.

[8] OTSUKA, K., WAYMAN, C.M., Shape Memory Materials, Cambridge University Pres, Cambridge, 1998.

[9] KAJIWARA, S., "Characteristic Features of Shape Memory Effect and Related Transformation in Fe based Alloys", Materials Science and Engineering: A, 273-275, 67-88, 1999. 